\title{
Resident's Issues and Interactions with Grid-Connected Photovoltaic Energy System in High-Performing Low- Energy Dwellings: A User's Perspective
}

\author{
David M. Whaley ${ }^{1}$, Stephen R. Berry ${ }^{1}$, Trivess L. Moore ${ }^{2}$, Graeme A. Sheriff ${ }^{3}$, \\ Timothy R. O’Leary ${ }^{1}$ \\ ${ }^{1}$ University of South Australia, Adelaide, Australia \\ ${ }^{2}$ Royal Melbourne Institute of Technology, Melbourne, Australia \\ ${ }^{3}$ University of Salford, Greater Manchester, United Kingdom
}

\begin{abstract}
Solar PV systems have become common-place in many cities and regions, and is a core technology in purpose-built low-energy homes, but evidence is emerging that in many cases electricity output may be significantly lower than expected. Information from in-home energy monitoring systems, interviews and informal discussions with residents has shed some light on the experiences and issues faced by the end-user, particularly those associated with operating a solar PV system to achieve a low-carbon lifestyle. Case studies of residents in different ownership and income situations, and from three distinct housing developments in Australia and England are used to highlight end-user experiences. The study finds that the residents face a range of issues including the initial sizing and commissioning, a lack of solar knowledge and expected generation performance, as well as regulatory barriers that limit the opportunity to upgrade system size.
\end{abstract}

Keywords: solar energy, user experience, low-energy housing, comparison.

\section{Introduction}

The uptake of photovoltaic (PV) systems around the World for domestic application has been remarkably fast in the past decade, driven by a combination of policy action and the rapidly reducing cost of the technology. In Australia, the number of dwellings with PV has gone from a few hundred to over 1.84 million PV installations, with a combined capacity of over 7.8 gigawatts, in just a single decade [1]. Putting this in perspective, more than 20 percent of all Australian households now have a rooftop PV system, and in some regions the uptake is nearly one in every three homes.

This rapid transition to a paradigm of self-generation and local energy demand management is in complete contrast to the previous status quo of householder as an energy purchaser. In many cases, the end-user household has no experience of the new technologies, and little understanding of how sunlight is converted into usable power for their domestic needs. This should not be not surprising as households have traditionally been focused on enjoying energy services rather than supplying the electricity market.

This paper explores the end-user experience of households, in the context of purpose-built low-energy homes, suddenly becoming the operator, and in some cases the owner, of a grid-connected power generation plant. This paper utilises case study material from households in Australia and the United Kingdom to address the research question: are households comfortable being responsible for domestic power generation. 


\section{$2 \quad$ Literature Review}

\subsection{Growth in domestic scale PV uptake}

Since the introduction of the Australian Mandatory Renewable Energy Target (RET) in 2001 with an original target approximating $5 \%$ of total electricity generation, later expanded to $20 \%$ renewable energy by 2020 , Australia has seen a significant uptake in domestic PV systems. Similarly, many other countries or regions have established renewable energy targets that have contributed to the uptake of domestic PV systems.

In Australia, rapid growth in solar PV uptake took-off from about 2008 when a number of State Governments added new incentives in the form of feed-in tariffs to supplement incentives from RET, and exploded in 2011 when the RET incentive was increased fivefold [2]. This acceleration in uptake has been supported by improving economics associated with ever-growing production volumes and improvements in unit efficiency $[3,4]$. As the economics of PV systems has improved the average size of domestic rooftop systems installed in Australia has increased from about $2 \mathrm{~kW}_{\mathrm{p}}$ in 2010 to about $6 \mathrm{~kW}_{\mathrm{p}}$ in 2018 [1].

\subsection{Performance of grid-connected PV systems}

While there is increasing evidence about the economic, energy system and environmental benefits of installing rooftop PV systems, there is also research which finds that some systems underperform [8-11]. In the UK, it was found that $4.1 \%$ of systems suffered long-term underperformance relative to their nominal efficiencies [9]. Other studies $[10,11]$ identified dozens of fault types a range of PV system components including modules, connection lines, converters, and inverters, each leading to serious underperformance in system efficiency and energy yield.

The researchers in the Australian study [8] used two main methods to determine faults, the first was to examine high-resolution (minute) gross solar energy data, and gauge whether the peak output on a clear day at solar noon seemed about right, or too low. This method requires knowledge of the sun's path and zenith angle relative to the panel, and is far too complex for the average end-user.

The second method compared the inverter output power for each minute of a 12month monitoring period, of the suspected faulty system to that of a known working system. Comparing the frequency vs. output power on a semi-logarithmic scale clearly shows if a system's output is significantly lower than a comparable system. This method is also too complicated for the average end-user, and requires additional data.

Once the suspected faults were investigated and rectified by the PV system installers, significant improvements in gross solar energy were seen for these houses, when comparing monthly gross solar energy generation for a 12-month period before and after the fault was investigated. This could be understood by the average end-user providing they had access to monthly monitored data, which the households in this case did. This highlights the need for consumers to have a better understanding of how their PV system works and what to do if there are issues. Otherwise we face a situation where millions of houses have this technology installed, but are not getting full benefit from it. This paper looks to explore some of these challenges. 


\section{Case Studies and Methodologies}

\subsection{Lochiel Park Green Village (South Australia)}

The Lochiel Park Green Village is purpose built low energy residential development, designed to significantly reduce energy use and associated greenhouse gas emissions [12]. All Lochiel Park homes include roof-mounted grid-connected solar photovoltaic systems, solar hot water systems, relatively high levels of passive thermal comfort design, water and energy efficient appliances and equipment, and other technologies designed to reduce both annual and peak energy demand. A comprehensive list of these household features is summarized in [13].

These houses are designed to achieve a Nationwide House Energy Rating Scheme (NatHERS) star rating of 7.5 stars, which is significantly improved over the current new build requirement of 6 stars (a predicted heating and cooling energy load of 58 vs. $96 \mathrm{MJ} / \mathrm{m}^{2}$ [14]); at the time the project was conceived newly constructed houses were only required to be built to 4 stars $\left(165 \mathrm{MJ} / \mathrm{m}^{2}[14]\right)$. The average PV system is rated at about $2.2 \mathrm{~kW}_{\mathrm{p}}$, as the urban design guidelines [15] stated that a minimum of $1.0 \mathrm{~kW}_{\mathrm{p}} / 100 \mathrm{~m}^{2}$ of habitable floor area was required; the average habitable floor area is $202.3 \mathrm{~m}^{2}$ [13]. Although this was the minimum required, purchasing and installing larger PV systems was at the time a costly exercise, given these houses were largely constructed between 2010-2012. The combined installed PV systems have provided $65.2 \%$ of the houses electrical energy demand to date, and that to make these house net zero energy, the PV system size required for the average house should be $2.75 \mathrm{~kW}_{\mathrm{p}}+1.0 \mathrm{~kW}_{\mathrm{p}} / 100 \mathrm{~m}^{2}$ of habitable floor area [16].

Each house in Lochiel Park is also fitted with a monitoring system, which includes an in-home feedback display, a programmable logic controller, and a variety of intelligent meters and sensors [17, 18]. The monitoring system collects water, gas and electrical energy usage and gross solar generation, each minute.

\section{Methodologies.}

Lochiel Park has been the subject of an ongoing research program since its initial habitation in 2009. The residents have participated in two interview processes relevant to this paper. Firstly, semi-structured interviews were carried out with 25 households in 2013 as part of research exercise designed to understand their perception of their homes energy, water and thermal comfort performance, and their interaction with various technologies and systems. Secondly, a modified oral history approach was applied with 14 households in 2017 to explore their housing histories from childhood to current experiences, encouraging them to reflect on strategies and practices to achieve thermal comfort. In addition, the monitored monthly PV system output data of all houses was examined between 2011 and 2017, using a methodology similar to [8], to identify any periods of prolonged failure of the PV systems.

\subsection{Catalyst Housing, Horsham (regional Victoria)}

The Catalyst housing development consists of four low-energy houses built by the Department of Health and Human Services. This department within the State Government of Victoria is responsible for providing subsidised housing for low-income households who would otherwise be priced out of the rental market. As part of a review of their 
internal minimum building performance requirements for new dwellings, they funded a demonstrative exemplar development in Horsham to evaluate outcomes for the occupants and the Department. The development was completed in 2012 and was built to a 9 NatHERS Stars thermal comfort standard $\left(25 \mathrm{MJ} / \mathrm{m}^{2} / \mathrm{yr}\right.$ vs. 6 Star build $110 \mathrm{MJ} / \mathrm{m}^{2} / \mathrm{yr}$ for that climate zone [14]). Other house features to achieve the low-energy outcome include: reverse brick veneer construction to increase internal thermal mass; doubleglazed windows; improved ceiling and wall insulation levels; $1.5 \mathrm{~kW}_{\mathrm{p}}$ grid-connect photovoltaic system. The householders were offered a feed-in tariff of $60 \mathrm{c} / \mathrm{kWh}$.

\section{Methodology.}

A three-year evaluation of the housing was conducted between 2012-2015 [19]. Each dwelling was monitored for energy consumption, solar energy generation, water consumption (mains and rainwater), temperature and humidity data. A cost-benefit analysis was undertaken based upon the monitored data and actual building cost data.

In addition to monitored data, semi-structured [20] interviews were conducted with the households annually. Interviews explored the occupants' experiences of living in a low-energy dwelling and included topics such as how the occupants used the dwellings, how much they cost to operate the dwelling, thermal comfort, and health and wellbeing. The evaluation also included seven control houses built to the minimum housing energy performance standards at that time, i.e. 6 stars. The results regarding the electrical energy usage and PV generation are reported in Section 4.2, whilst those regarding other elements of the evaluations are further examined in [19].

\subsection{Henley Way (Rotherham, United Kingdom)}

Henley Way is an estate that is owned and operated by South Yorkshire Housing. The 'eco-houses' within the estate incorporate several sustainable features including: double-glazed windows; high levels of insulation; and a combined thermal solar thermal and PV collector. The PV systems are rated at 3.02 or $3.75 \mathrm{kWp}$, are installed with cell optimisers that optimise the output power of each cell in the case of partial shading. Each system included a gross solar meter (situated inside), an electrical schematic of the system 'as built', and with a portable cordless monitor.

The portable monitor acts as a pseudo traffic light (green, yellow and red LEDs) that displays the real-time cost of the household's electricity, rather than traffic. That is, a green LED indicates that the electricity being consumed is free, whilst red indicates that this is costing the tenant money.

\section{Methodology.}

Semi-structured interviews were held with two householders (H1, H2). This style of interview utilises simple open-ended questions to provide a replicable focus on the research question, and were designed to collect the experiences and perceptions from within their own storytelling as opposed to answering survey questions determined by the interviewer.

\subsection{Case Study 4: Adelaide (South Australia)}

Informal discussions with four householders (A1-A4), who have recently built, renovated or moved into high-performing houses, were conducted. The PV systems ranged from $1.5-5.5 \mathrm{~kW}_{\mathrm{p}}$, and used centralized or micro-inverter topologies; one household had 
battery storage. The feedback mechanisms in place were simple compared with those in Lochiel Park, which include: a SmartPhone app linked to micro-inverters; blinking or solid coloured battery-mounted LEDs; and LCD screens fixed to inverters.

\section{$4 \quad$ Results and Discussion}

\subsection{Case Study 1: Lochiel Park (SA) Interview Findings.}

Structured interviews were carried out with 25 households in 2013, who were on the 'generous' feed-in tariff that is locked in until June 2028. Subsequently, these households benefit financially by exporting as much of their solar energy during the day as possible, and to import from the grid at times when the sun was not shining. However, at the conclusion of their feed-in tariff arrangement or as electricity tariffs continue to increase, it is expected that this practice may be reversed. It is unclear whether residents are aware of this or if they will subsequently alter their current export behavior.

The majority (88\%) of residents felt that their in-home display / energy monitoring system was valuable, and $60 \%$ would choose to have a monitoring system in a future home of theirs; the latter was generally subject to cost, and if data could be accessed remotely, via spreadsheets, emails or a SmartPhone or laptop interface. The majority (92\%) used this to check their electrical consumption and PV energy generated; yet $52 \%$ mentioned that they did not track their usage or generation as such. Very few households $(20 \%)$ indicated that they also track their water and gas consumption, mainly as these parameters were perceived too difficult to read. In contrast, $8 \%$ of households indicated that they did not interact with their monitoring system, nor did they see value in this in their current or potential future homes. This is despite $36 \%$ of people reporting that an energy monitoring system could or had been used to identify faults, such as water and gas leaks. Surprisingly, $12 \%$ of households mentioned that they could potentially identify inverter faults using this monitoring system, yet nobody knew how to identify if their PV system output power was correct. Finally, $4 \%$ used their monitoring system to maximise their solar feed-in tariff, whilst $12 \%$ mentioned that they would like the ability to compare their data with others.

\section{Findings from Monitored Data and Modified Oral History.}

Although interviewees reported using their monitoring systems to identify faults and check their electricity usage and solar output, a number of inverter faults were seen when analyzing the data; two cases are discussed here. Household L35OT did not notice that their inverter had tripped, as they do not engage with their monitoring system. They were only alerted 13 months later when they received a larger than expected utility bill and queried their retailer. It is unclear whether the inverter issue has been resolved, as this monitoring system has since failed and data from this house is no longer collected.

Household L45FT experienced a similar inverter issue, however it is known that the monitoring system is functioning correctly. The monthly solar data is shown in Fig. 1, and indicates an inverter issue in January 2017 went unresolved in 2017. Data from 2018 shows that the issue was resolved in early January 2018, however this is 12 months after the event. It is thought that the residents were also alerted by a bill. 


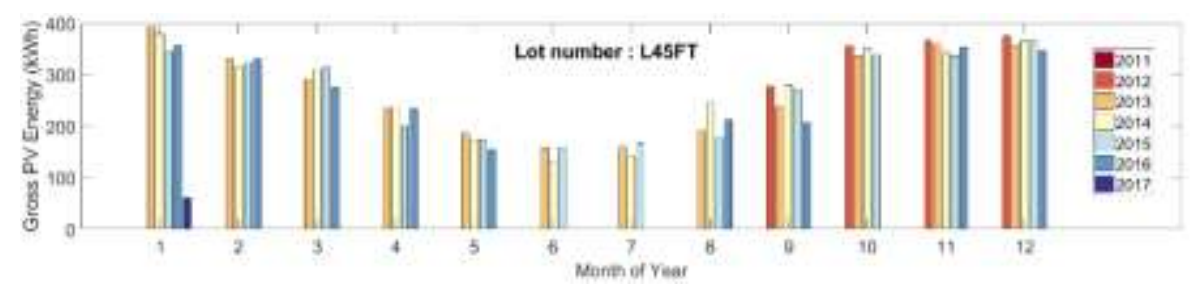

Fig. 1. Monthly solar output energy for L45FT, showing lack of solar data from Jan. 2017.

Although many of those interviewed indicted that they checked their solar output, endusers are unable to effectively gauge whether their system is performing at the expected level. This is evident as to date not one household have identified that their PV system is generating less power than expected, compared to the five systems that were correctly identified by the researchers. Two households are discussed here.

Household L13TN, as with each of the five cases identified with a fault, was producing significantly less peak output power than expected. Despite that analysis in [8] that showed this $2.2 \mathrm{~kW}_{\mathrm{p}} \mathrm{PV}$ system was operating as though it was rated at $0.9 \mathrm{~kW}_{\mathrm{p}}$, the installer refused to acknowledge this engineering analysis refused to return to the house to inspect this system. He claimed that the lower peak output power at solar noon was expected for that time of year, which was not the case. Eventually a third party investigated this system, where they discovered several issues with the original installation. Upon addressing these, the system gross solar output energy more than doubled, as expected. The system now appears to be operating as a $2 \mathrm{~kW}_{\mathrm{p}}$ system.

Household L30OO, was investigated in [8] where after a system fault was fixed in early January 2012, was shown to produce $34.3 \%$ more energy than the previous 12 months monitored. This is clearly seen in Fig. 2, which shows the improved monthly output for years 2012-2014. The figure also shows that the issue fixed in January 2012 resurfaced in January 2015. It is unclear whether this issue has since been resolved as this monitoring system stopped reporting data in November 2015.

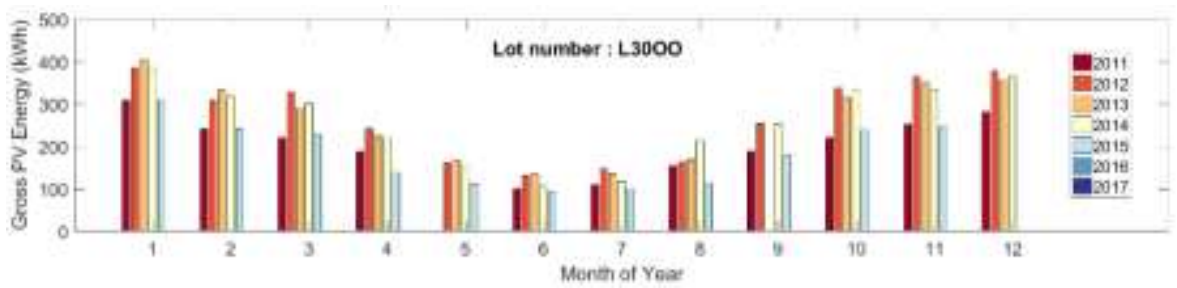

Fig. 2. Monthly solar output energy for L30OO, showing improvement from Jan. 2012.

It is evident that solar PV was a new technology to the residents for which they had little understanding of how the system operated and the likely output, with some mentioning had they known the benefits more clearly they would have purchased a larger capacity system. Some residents noted the impact of falling PV system cost. For example, one resident stated "the cost for all our solar stuff was quite exorbitant compared to what you have to pay for the same systems now". One householder was looking to the future and increasing the amount of solar panels so that they could become a net electricity exporter and achieve self-sufficiency through the acquisition 
of battery storage technology, noting it was "coming down to a point where it starts to makes sense, economically as well as environmentally”. However, some residents raised concern that increasing the PV system capacity would void the "very generous government subsidy" they received and still enjoyed, This highlights the ongoing complexity attached to multiple and sometimes competing policy support mechanisms.

The unfamiliar technology required a period of learning and the development of new practices, particularly related to achieving the best economic outcome. For example, one household discussed changing their summer air-conditioning practices to what they thought would minimise costs, stating "we only use the air conditioner when we have to" ... "if it's a stinking hot day and my air conditioner when it's running flat-chat will run about $3.5 \mathrm{~kW}$ an hour... my solar panels can produce I think about $2.2 \mathrm{~kW}$... I run my air conditioner then and cool the house down, because I'm only having to import $1.5 \mathrm{~kW}$." In reality, given the relatively high value of the feed-in tariff, it may have been financially better for the resident to run the air-conditioner when the sun had set.

The most commonly discussed experience of solar PV was its impact on energy bills. For example, one household described how they "can't remember ever pay a bill for electricity except for a small period when the DC/AC inverter broke down and needed replacement.". It was also evident that PV was discussed in the context of the overall energy strategy and performance of the homes, with residents aware that the energy efficient design and appliances made it possible for the PV to supply their demand.

\subsection{Case Study 2: Horsham (regional Victoria)}

The overall electricity consumption of the four low-energy houses (LEHA-LHED) is shown in Fig. 3, along with a comparison with the Department standard. On average, these houses consumed 23\% less electrical energy than the Department standard, which was similar to that consumed by the control houses. However, when the impact of the PV systems were included, the LEH purchased (on average) $65 \%$ less electrical energy than the Department standard, and 54\% less electrical energy than the control houses.

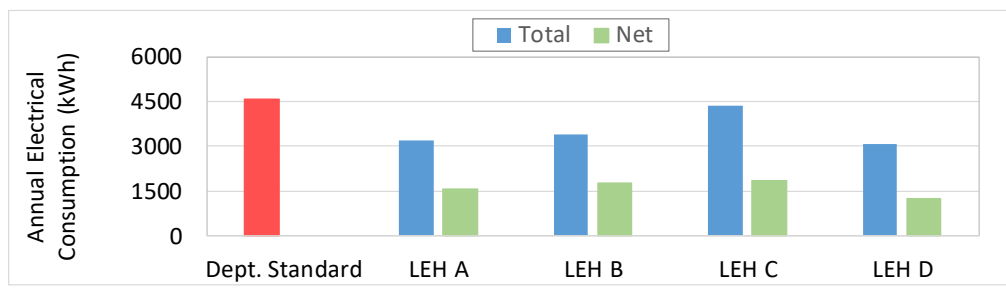

Fig. 3. Comparison of total and net electrical energy consumption of low-energy houses (LEH) A-D with the Department standard, showing the impact of the grid-connected PV systems.

This reduction in purchased electricity was not something noted as a technical outcome; it also had tangible benefits for the households. Three of the four households spoke about the significant reduction of their energy bills, compared with their previous dwellings. The fourth household had not lived out of home previously, and as such was unable to compare. Due to the size of the PV system and high feed-in-tariff for excess energy generated, each household found themselves in credit regarding their energy 
bills for at least some of the year; two households were in credit at all times. One occupant stated 'Look I haven't paid off my power bill in six months and I'm still in credit...\$882 [currently in credit]".

The cost-benefit model calculated that the households were about $\$ 1,000 /$ year better off, compared to a Department standard home, due to the improved sustainability of the low-energy houses, including the grid-connected PV system. This was noticed by the households who found they had additional money to spend on alternatives, such as birthday presents or dining out.

This benefit was not just relating to the financial elements for the households but extended to health and wellbeing especially in relation to managing living costs. As one household said "...It is easier...I don't have to stress that, "Oh my God, I'm going to have a power bill come in".

However, while there were clear benefits for the households in terms of finances there were some challenges relating to the PV systems. This included confusion when they moved in, regarding the correct installation and commissioning procedures. Subsequently, the Department organised for the final commissioning and connection of the systems as the households did not have the capacity to undertake this task. There have also been some issues with the technology itself. In one instance during the first year there was a faulty panel which was not identified for several bill cycles, as the householder did not understand the reason for reduced solar related credits in their bill. The PV system of another household was accidentally switched off when some other work was being done to the house, which similarly was unnoticed for several months. In this case, the resident estimate they have missed out on $\$ 200$ of feed-in credits; it is unclear how much self-consumed 'free' solar energy they also missed out on.

This highlights challenges for households and PV system designers to understand how these work, and how to identify any issues with performance. These low-energy houses did not have in-home displays or an option for monitoring the energy generation. Therefore, these householders were unable to determine any issues with performance, providing they interacted and understood any feedback offered to them.

\subsection{Case Study 3: Henley Way (Rotherham, United Kingdom)}

The two households in Henley Way revealed that they thoroughly enjoyed living in their 'eco-house' and both mentioned the high levels of thermal comfort experienced and how they now used their heating systems for only a small portion of time compared to their respective previous residences. This translated directly into reduced energy consumption and utility bills, particularly as these houses now provided a significant portion of heat and electricity from their roof-top solar thermal / electrical system.

Both householders discussed how they interacted with their portable traffic light (electricity cost monitoring) system, where they would consult their display help make decisions about when to use certain high-powered electrical appliances.

Household $\mathrm{H} 1$ indicated that their combined electricity, water and gas bill was now $£ 50 /$ month, whereas their gas bill alone exceeded this in their previous house; despite using the same utility provider and tariffs. Household $\mathrm{H} 2$ mentioned that due to the poor solar feed-in tariffs, dropping from 12 to $4 \mathrm{p} / \mathrm{kWh}$, they registered their PV system as a power station generator. This offers an income of approximately $£ 1,000$ / year, however requires frequent reporting of generation data to the utility. 


\subsection{Case Study 4: Other South Australian Houses}

Householder A1 is an expert in solar energy monitoring and is familiar with methods that evaluate the performance of PV systems. This householder interacts with a SmartPhone app daily, to decide when to use high-powered electrical appliances, and to ensure his PV system is generating energy. He also uses forecasts and delay timers to ensure appliances, such as the dishwasher, are powered by free solar generated energy when he is not home. The app also gives an accumulated energy generation figure, which has allowed him to demonstrate that his PV system had generated the solar energy expected since it was commissioned. This process does require knowledge of the expected energy output for various Australian cities, as well as the impact of roof pitch and compass bearing. The average PV system end-user could not easily determine this.

Householder A2, revealed that a monitoring system, was recently installed when two batteries were installed and commissioned. This monitoring system displays household energy usage, solar generation and battery stator of charge on a SmartPhone app; it also has the capability to alert the installer of any battery issues. This end-user has seldom engaged with the app, unlike the existing inverter-based monitoring system, which was never accessed due to the complexity in accessing this via Bluetooth.

The householder was informed how to use of their PV system and batteries to reduce utility bills. Despite this, the advice was ignored as she was unwilling to change behavior and refer to the app, or look outside a window to make decisions about energy usage. This is puzzling, given that saving money was the motivation behind these purchases.

The importance of regular interaction with the app or battery LEDs was shown on a follow up visit, when it was revealed that the PV inverter circuit breaker had tripped five days earlier, and the batteries had hence fully discharged themselves. Despite this and the relatively simple display on the batteries that indicated this, the householder was unaware of any issues, nor was she contacted by the installer. It is likely to have gone unnoticed until the next high bill arrived, as with the Lochiel Park households.

Householder A3 recently considered expanding his PV system, however, given this would mean giving up the initial 'generous' solar feed-in tariff. Coupled with the inverter life expectancy of about 10 years, this householder decided to remain on the initial feed-in tariff until the inverter must be replaced. This householder suspects his system is underperforming, however this cannot be determined as solar data cannot be extracted from the outdoor wall-mounted inverter, due to lack of communication capabilities. The householder could only ever monitor the real-time output power and accumulated energy output by reading the LCD display on the inverter, however given this screen is exposed to direct sunlight, it has faded with time and now cannot be read. This was similarly reported by household $4 \mathrm{~B}$.

Householder A4 had suspected their PV system output power was lower than expected for a number of years. After utilizing a 'free' online solar system checkup, which proved inconclusive, they presented personally monitored data to their installer, which showed that 10 of 22 inverters were faulty. Following recent threats of legal action, resulting from lack of installer action, the supplier replaced the micro-inverters for each panel and the householder stated "[installer] finally admitted that our micro-inverters were faulty. They have in the last few months been replaced and we are showing considerable more electricity being generated and being put back into the grid". 


\subsection{Discussion}

Given the case studies presented here, the average end-user, and some installers does not have the knowledge to accurately assess the performance of PV systems or identify inverter issues. This was seen across the case studies particularly in South Australia where residents had access to complex monitoring systems, and relatively simple feedback displays. In two case studies, inverter issues or reduced output issues were identified by higher than expected bills. These were noticed after several billing cycles, likely due to generous feed-in tariffs and credits that eroded over time. In the case of the Victorian household, they did not have access to any alternative feedback mechanisms.

The fault that caused lower output power for one household in Lochiel Park, returned three years after it was fixed, which has not since been rectified. The end-user is likely unaware of an issue, as it is doubtful they compare their data from the past five years.

The issue here is how much the end-users need to engage with their energy generation to ensure it is correctly working. This could be done through a monitoring system as in Lochiel Park, but if occupants are not aware of what to look for, or how differences in climatic conditions could impact on the system, then it is difficult for them to identify if there is an issue. With the increasing popularity of micro-inverters, many of which are now monitored by the product manufacturer, this could be a way to help address such challenges. Micro-inverters allow for the rest of the system to keep working if a single panel or inverter fails; these are often remotely monitoring by professionals.

\section{Conclusions}

This paper used monitored data collected from energy monitoring systems, interviews and informal discussions with residents in both Australia and England to investigate whether households comfortable being responsible for domestic power generation. The conclusions from this work include:

- End-users value feedback, yet despite best intentions and a range of simple or complex feedback displays used, they are unable to identify issues that impact the performance of the energy generation system, including inverter issues.

- End-users that do not understand or that do not engage with feedback, rely on high bills to indicate issues. In two cases a delay of 12 months was shown.

- Once installers were contacted regarding a fault, the majority attended and fixed the issues, which resulted in significant improvements in output power and energy.

- One end-user deemed that operating a house with a PV system was too difficult, and did not want to alter their behavior (look out of a window) to make decisions about energy usage, yet they had purchased a PV and battery system to save money.

- Simple feedback displays that mimic traffic lights are easy for users to understand, and were hence used to make decisions regarding when to use certain appliances.

\section{Acknowledgements}

The authors wish to recognise the kind assistance of Dr Aimee Ambrose, Professor Barry Goodchild and Dr Angela Maye-Banbury from Sheffield Hallam University for facilitating the interviews discussed in this paper. Funding for this project was provided by the Australian Technology Network of Universities Science and Research Priorities Seed Fund. The authors wish to also thank the support of all householders interviewed. 


\section{References}

1. Australian PV Institute (2018). http://pv-map.apvi.org.au/analyses , last accessed 2018/05/30.

2. Chapman, A., McLellan, B., Tezuka, T.: Residential solar PV policy: An analysis of impacts, successes and failures in the Australian case. Renewable Energy 86, 1265-1279 (2016).

3. Mauleón, I.: Photovoltaic learning rate estimation: Issues and implications. Renewable and Sustainable Energy Reviews 65, 507-524 (2016).

4. de La Tour, A., Glachant, M., Ménière, Y.: Predicting the costs of photovoltaic solar modules in 2020 using experience curve models. Energy 62(0), 341-348 (2013).

5. https://www.sa.gov.au/topics/energy-and-environment/energy-bills/solar-rebates-andpayments, last accessed 2017/02/23.

6. Energy Matters. https://www.energymatters.com.au/rebates-incentives/feedintariff/\#southaustralia , last accessed 2017/07/27.

7. Energy Matters. https://www.energymatters.com.au/renewable-news/solar-panel-installation-australia-record/, last accessed 2018/01/31

8. Whaley, D., Pudney, P., Grantham, A., Saman, W.: Performance of a cluster of low-energy housing rooftop PV systems: theoretical vs actual output. In: Proceedings of the 52nd annual conference. Australian Solar Energy Society, Melbourne (2014).

9. Taylor, J., Leloux, J., Hall, L.M.H., Everard, A.M., Briggs, J., Buckley, A.: Performance of distributed PV in the UK: a statistical analysis of over 7000 systems. In: $31^{\text {st }}$ European Photovoltaic Solar Energy Conference and Exhibition, Hamburg (2015).

10. Madeti, S., Singh, S.: A comprehensive study on different types of faults and detection techniques for solar photovoltaic system. Solar Energy 158, 161-185 (2017).

11. Mellit, A., Tina, G.M., Kalogirou, S.: Fault detection and diagnosis methods for photovoltaic systems: A review. Renewable and Sustainable Energy Reviews 91, 1-17 (2018).

12. Berry, S., Davidson, K., Saman, W. The impact of niche green developments in transforming the building sector: The case study of Lochiel Park. Energy Policy 62, 646-655 (2013).

13. Berry, S., Whaley, D., Davidson, K., Saman, S.: Near zero energy homes - What do users think?. Energy Policy 73, 127-137 (2014).

14. Nationwide House Energy Rating Scheme, http://nathers.gov.au/files/publications/NatHERS\%20Star\%20bands.pdf, last accessed 2013/07/03.

15. Land Management Corporation.: Lochiel Park, Campbelltown: Urban Design Guidelines. (2009). Available: http://joshshouse.com.au/wp-content/uploads/2014/12/Lochiel-Park-Urban-Design-Guidelines.pdf , last accessed 2015/01/12.

16. Berry, S., Whaley, D., Saman, W., Davidson, K.: Reaching to Net Zero Energy: The Recipe to Create Zero Energy Homes in Warm Temperate Climates. Energy Procedia 62, 112-22 (2014).

17. Whaley, D., Saman, W., Halawa, E., Mudge, L.: Lessons learnt from implementing intelligent metering and energy monitoring devices in a new housing development. In: Proceedings of the 48th annual conference. Australian Solar Energy Society, Canberra (2010).

18. Saman, W., Whaley, D., Mudge, L., Halawa, E. Edwards, J. The intelligent grid in a new housing development, University of South Australia, Adelaide (2011).

19. Moore, T., Strengers, Y., Maller, C., Ridley, I., Nicholls, L., Horne, R.: Horsham Catalyst Research and Evaluation - Final Report. Retrieved from Melbourne (2016).

20. Matthews, B., Ross, L.: Research methods: a practical guide for the social sciences, Pearson Longman, Essex (2010). 